Revista de Economia Política, vol. 29, $n^{\circ} 3$ (115), pp. 252-253, julho-setembro/2009

\title{
Comentário sobre o artigo intitulado "Banking and regional inequality in Brazil: an empirical note”
}

RODOLFO HOFFMANN*

O artigo de Lima e Resende (publicado no volume 28 (4) 2008 desta Revista de Economia Política) usa o índice $T$ de Theil como medida da desigualdade da distribuição dos empréstimos em relação à distribuição dos depósitos. Sendo $x_{i}$ a participação da $i$-ésima unidade nos depósitos e $y_{i}$ a respectiva participação nos empréstimos, a medida de desigualdade de Theil é

$$
T=\sum_{i=1}^{n} y_{i} \ln \frac{y_{i}}{x_{i}}
$$

Essa é a expressão (3) no artigo de Lima e Resende (2008), apenas substituindo o símbolo $I(y, x)$ por $T$.

Quando essa medida é usada na análise da distribuição da renda, $x_{i}$ é a fração da população e $y_{i}$ é a respectiva participação na renda total $\left(\operatorname{com} x_{i}=1 / n\right.$ no caso de dados individuais).

Hoffmann e Kageyama (1987) usaram a medida de Theil para analisar a desigualdade da distribuição do crédito rural, em relação ao valor da produção agropecuária. Neste caso, para analisar a desigualdade regional na distribuição do crédito rural no Brasil, $x_{i}$ é a participação da $i$-ésima Unidade da Federação no valor total da produção agropecuária e $y_{i}$ é a respectiva participação no total de crédito rural.

Se $x_{i}$ e $y_{i}$ têm as propriedades matemáticas de probabilidades (ou de frações do total para uma variável não-negativa), demonstra-se que $T \geq 0$. A demonstração está em Theil (1967, p. 28) e também pode ser encontrada em Hoffmann (1998, pp. 103-104). O valor mínimo é $T=0$, que ocorre quando $x_{i}=y_{i}$ para todo $i$.

Não consigo entender, então, como Lima e Resende (2008) obtiveram valores

\footnotetext{
* Instituto de Economia da Universidade Estadual de Campinas. E-mail: rhoffman@esalq.usp.br.
} 
negativos para o que denominam "Theil's expected information index" ou índice RFI (regional financial inequality).

Se os valores de $x_{i}$ e $y_{i}$ foram "redefinidos" e isso levou a uma medida negativa, é claro que não se trata mais da medida de desigualdade proposta por Theil (1967). Mas nesse caso seria necessário definir claramente a nova medida e verificar se ela tem as propriedades desejáveis de uma medida de desigualdade.

As medidas usuais de desigualdade são iguais a zero no caso de perfeita igualdade. Assim, tenho dificuldade em imaginar o significado de uma "desigualdade negativa". No caso dos bancos privados, Lima e Resende (2008) obtêm uma série de valores do seu índice RFI que são todos negativos e com valores absolutos mais elevados no fim do período. Matematicamente, os valores são mais baixos no fim do período, mas os autores interpretam o resultado como "higher inequality towards the end of the sample period". Essa afirmativa não pode ser aceita sem uma análise mais cuidadosa da nova medida de desigualdade.

\section{REFERÊNCIAS BIBLIOGRÁFICAS}

HOFFMANN, R. (1998) Distribuição de renda: medida de desigualdade e pobreza. Editora da Universidade de São Paulo.

HOFFMANN, R. e KAGEYAMA, A.A. (1987) Crédito rural no Brasil: concentração regional e por cultura. Revista de Economia Rural. 25 (1): 31-50.

LIMA, M. e RESENDE, M. (2008) Banking and regional inequality in Brazil: na empirical note. Revista de Economia Política 28 (4): 669-677.

THEIL, H. (1967) Economics and information theory. North-Holland. 